\title{
Chapter 11 \\ The Marginal Poor and Their Dependence on Ecosystem Services: Evidence from South Asia and Sub-Saharan Africa
}

\author{
Pushpam Kumar and Makiko Yashiro
}

\begin{abstract}
In this chapter the authors employ a meta-study to explore why it is critical to address the degradation of ecosystems for poverty alleviation, especially in South Asia and Sub-Saharan Africa. The authors also investigate the linkages between ecosystem services and aspects of extreme poverty. Their findings suggest that the poor are often more vulnerable to the loss of ecosystem function that restricts the supply of natural goods and services. The poor depend upon ecosystem services, but the nature of this dependence is necessarily not uniform throughout the year. The poor also tend to benefit less from environmental conservation efforts than those who are not poor. The dynamic patterns of dependence on ecosystem services of the poor and their coping strategies require regionally specific and in-depth evaluation.
\end{abstract}

Keywords Ecosystem services • Poverty alleviation • Vulnerability • Linkages • Agriculture

\subsection{Introduction}

Poverty may be defined as pronounced deprivation in well-being, which not only signifies material deprivation as measured by an appropriate concept of income or consumption, but may also include low achievement in education and/or health, high vulnerability to and/or exposure to risk, and a lack of socio-political representation or powerlessness (World Bank 2000). Multiple dimensions of well-being were also highlighted in the conceptual framework used for the Millennium

\footnotetext{
P. Kumar $(\square) \bullet$ M. Yashiro

Ecosystem Services Economics Unit, Division of Environmental Policy Implementation, United Nations Environment Programme, P.O. Box 30552, Nairobi 00100, Kenya

e-mail: pushpam.kumar@unep.org; makiko.yashiro@unep.org
} 
Ecosystem Assessment (MA 2005a) including: security, basic materials for living, health, social relations, and freedom of choice and action. The conflicting interests among various stakeholders who depend on common ecosystem services and products highlight the political economy in regions with high levels of poverty like South Asia and Sub-Saharan Africa, emphasizing the fact that powerlessness is an important dimension of poverty because it is the powerless who suffer most when such conflicts arise. The fact that the poor are often more critically affected by ecosystem degradation due to reduced access to resources and a lack of alternatives is usually evident (ESPASA 2008). Migration and finding alternative livelihoods (under duress rather than choice) are the most prevalent coping strategies for the natural resource dependent poor who lose these conflicts, but these strategies often result in homelessness, lowered self-esteem, and feelings of alienation and/or detachment.

In this paper we explored why, in this context, it is critical to address the degradation of ecosystems for poverty alleviation, especially in South Asia and Sub-Saharan Africa. We also investigated the linkages between ecosystem services and aspects of extreme poverty. Subsequently we synthesized literature evidence of the dynamic relationships between the incidence of poverty and the state of ecosystems from the regions of South Asia and Sub-Saharan Africa.

\subsection{Why Is It Important to Address the Marginal Poor to Achieve Poverty Alleviation?}

There is great variation among countries in the achievement of poverty alleviation. For example, among the five countries of South Asia (Bangladesh, Bhutan, India, Nepal, and Pakistan), all except Pakistan have experienced a declining trend in the incidence of poverty - in terms of national poverty lines - since the mid-1990s.

According to the 1997 Human Development Report issued by the United Nations Development Programme, poverty is usually worse in drier zones relative to more humid zones (UNDP 1997). The MA (2005b) also reported that in arid and semi-arid lands, people's dependence on ecosystem services is often high because of the limited availability of alternative livelihood options in fragile environments. In India arid and semi-arid regions include 125 districts in over 12 states that are officially identified as drought prone areas under the Drought Prone Area Programme, and 32 of these districts have either a high or very high incidence of poverty. The nonincome dimensions of poverty are very much evident in drought prone regions: livelihood security is low on account of the high instability of crop production and there are significant social costs on account of large-scale inter-state population movements that result from resulting food shortages (Mehta and Shah 2006).

In South Asia poverty is primarily a rural phenomenon, with the majority of the population living in rural areas and primarily dependent on agriculture for income and employment (World Bank 2008). The ability of the rural poor to sustain their livelihoods is generally constrained due to adverse environmental conditions: high 
ecological vulnerability, low productivity of natural resources, and limited access to land and other resources (World Bank 2002). Poverty in forested regions of India, however, is also linked to widespread entitlement failure (Mehta and Shah 2006). The rural poor are also hampered by their lack of access to markets, reliance on raindependent agriculture, and the prevalence of threats to food security. For the rural poor access to a variety of natural resources is often critical for sustaining livelihoods because they provide diversification options when environmental conditions change (Koziell and Saunders 2001). Chronic rural poverty in semi-arid regions of India has also been attributed to the negligible or inferior natural resource endowments that restrict the ability to augment income (Singh and Binswanger 1993).

\subsubsection{Vulnerability and Insecurity}

A key dimension of poverty is vulnerability, which reflects a household's resilience in the face of shocks and the likelihood that a shock will lead to a decline in wellbeing (World Bank 2008). Poor households are vulnerable to sudden and pronounced fluctuations in income that may arise due to poor health, market fluctuations, and natural calamities. Since most rural poor are dependent on agricultural livelihoods they are automatically the most vulnerable to climate-change induced risks of crop failure and livestock losses.

For example, vulnerability to natural disasters is fairly high in Bangladesh. During seasonal floods women and children become particularly vulnerable to related health impacts and wage laborers suffer from shortages of employment opportunities. For many rural households in Bangladesh riverbank erosion is a constant threat to their well-being. The impacts are severest among the landless and marginalized farmers. Hutton and Haque (2004) suggested that the displaced, particularly women, suffer mental stress because of social fragmentation and the difficulties of adjusting to the urban areas where they often immigrate.

Unanticipated environmental consequences of development projects have also often been a great source of misery for local communities. The construction of upstream projects may create downstream environmental hazards that are detrimental to livelihoods. For instance, the construction of embankments in the GangaBrahmaputra river basin to moderate flood impacts has caused large areas in the basin to remain in a semi-permanent waterlogged state, seriously affecting human health and agriculture (Bandyopadhya 2002).

The lack of explicit government policy on ecosystems services, the absence of a suitable accounting system, the general lack of awareness, and the lack of research evidence to convince policy-making authorities to recognize and institutionalize the management of ecosystem services have jointly played a role in the degradation of ecosystems in South Asia and Sub-Saharan Africa with negative impacts on the poor. Aberrations in ecosystem function such as unexpected flooding, long droughts, desiccation of springs, increased spread of invasive species on productive lands, and reduced productivity of natural resources like non-timber forest products or fish 
usually have the greatest impact on the poorest people who directly depend on these products for subsistence purposes.

Distortions take place in policy cases, like offering subsidies for fertilizers and pesticides to farmers to enhance crop productivity (for poverty alleviation), that are oblivious of the resultant negative impacts on soil quality. While the provision of natural ecosystems services is diminishing, demand is constantly growing. Furthermore, ecosystems are not treated in policy frameworks as 'natural capital,' with tremendous potential to generate employment and income.

\subsection{Links Between Ecosystem Services and Poverty}

The links between the status of ecosystems and human well-being, including the importance of various ecosystem services and products to human well-being, have been increasingly recognized in recent years (MA 2005a, b; ESPASSA 2008; Shackleton et al. 2008; Tallis et al. 2011). Furthermore there is a general consensus that poverty is a major contributor to environmental degradation (WCED 1987). That report (also known as the "Brundtland Report"), as well as the definition of sustainable development developed by the World Commission on Environment and Development (WCED), were landmarks in the sense that they identified direct links between environmental degradation and poverty in the context of economic development in developing countries, and that they called for collective action to address environmental threats and economic development goals as interrelated phenomena (Speth and Haas 2006). The World Bank joined the consensus with the 1992 World Development Report, which highlighted the dependence of poor families on natural capital for meeting their short-term livelihood needs, often leading to environmental degradation.

There is shared recognition that most natural ecosystems are in a state of decline, with negative impacts on human well-being, especially for those living in extreme poverty. The MA (2005a) findings highlighted significant negative trends in the delivery of many ecosystem services and concluded that these declines were barriers to achieving the Millennium Development Goals (MDGs). In fact many of the regions facing severe problems related to the deterioration of ecosystem services overlap with those facing significant challenges to achieving the MDGs.

Many of the world's poorest people live in rural areas and are highly dependent on ecosystem services and products, such as those that contribute to food production via agriculture, fishing, and hunting. As previously mentioned, people living in extreme poverty are highly vulnerable to ecosystem changes such as the availability or quality of water, or the loss of wetland and coral reef ecosystems that might increase the likelihood of coastal floods or storm damage. In addition to the goal of eradicating extreme poverty, the ability of ecosystems to supply services also has strong relevance in addressing other aspects of the MDGs, such as the goal of eradicating hunger, the reduction of child mortality, combating disease, and ensuring environmental sustainability (MA 2005a). At the same time, 
achieving many of the aspects of well-being that are linked with ecosystem services will directly or indirectly contribute to the attainment of a number of the MDGs (UNEP/IISD 2004).

\subsection{Global Evidence}

The relationships between poverty, the environment, and ecosystems have commanded a significant amount of attention by academics, non-governmental organizations (NGOs), development practitioners, and civil society. A number of influential studies (Dasgupta 1997; Pearce 2005; Barbier 2010) have dispelled the usual beliefs about the relationships between poverty and the environment rather than establish any profound new insight into these relationships. Conventionally it is assumed that the poor discount the future and are unable to act with regard to long-term interests, and hence are responsible for mining the soil, depleting the groundwater, and causing deforestation more than their wealthier counterparts (Dasgupta 1995). Many others believe that affluence increases the use of forest products, pollution generating products, and leads to a lifestyle that is more inimical to the existence of nature. Both perspectives are correct as well as wrong, as they happen to be purely contextually and culturally specific, and are dependent on: property rights regimes, the prevailing political climate, historical trends of resource use, relevant social and religious practices, and the aspirations of consumption fueled by the global market and investment conditions. While these drivers of change remain relevant to the relationships between poverty and the environment, the degree of association and dimensions of causality can be perceived in various ways, and the particular environmental resources or attributes linked to poverty also need to be considered.

It is important to mention that while natural resources remain self-explanatory, poverty here refers to absolute and chronic poverty, where the material conditions of people's lives are well below designated cut-offs, which indicates the limited ability to buy enough food for minimum caloric intake. Evidently this is a very conservative method of defining poverty and many aspects of well-being fall outside uni-dimensional definitions. Therefore poverty in such cases is a measure of the distance of people's actual condition from a state considered 'well,' but it does not necessarily reflect their well-being.

The facts remain that the unsustainable use of natural resources contributes to poverty, and on the other hand that poverty can also contribute to environmental degradation (Duraiappah 1998). To solve these problems both poverty alleviation and environmental policies need to be addressed. Many developing countries view the need for improved management of natural resources as part of the attack on the underlying causes of degradation and depletion, specifically excessive population growth and poverty, which are the main drivers of immigration into the remaining areas of natural habitat. Strong programs to reduce population growth rates and create jobs for unemployed and underemployed rural residents will be crucial to the 
long-term prospects of reducing environmental degradation, especially to reduce deforestation (Pfaff et al. 2000).

Many of the world's poor occupy the least resilient, most threatened environmental areas (Pearce and Warford 1993). There is also some evidence that the poor are more dependent upon common property natural resources than the rich (Jodha 1986). The assertion is often made that poor people have a greater tendency to overexploit natural resources like land, forests, and water, and thereby degrade them. This is based on the belief that the poor deplete natural resources at a greater rate than their more affluent counterparts because they have direct access to them and limited prospects of gaining access to other types of resources and economic opportunities. Additionally, because the poor struggle for their subsistence they are preoccupied with day-to-day survival, and are assumed to have limited incentives and capability for long-term planning or investing in management efforts that improve the sustainability of natural resource use over the long-term (i.e., soil conservation efforts). Thus the poor have little choice but to employ the natural resource use practices that fulfill their immediate subsistence needs, even if these practices are detrimental to those resources over the long-term.

Growing poor populations in precarious environments (i.e., ecologically fragile areas) are a major cause of the severe environmental destruction that has been documented in developing countries by numerous recent studies (Comim et al. 2009). The problems of poverty and environmental degradation are complicated and resolving them is made vastly more urgent by the relentless increase in the number of people living in developing countries. In many cases poor people must degrade their environment just to make ends meet, but in doing so they take not only from nature's bounty, but also from the well-being of future generations.

In addition to being agents of environmental degradation, the poor are also often the victims of environmental damage due to the fact that they often depend heavily on natural resources for subsistence, and therefore are generally more affected by environmental degradation than those who are not poor (Tallis et al. 2011). Due to this strong dependence of the poor on natural resources the degradation of ecosystems may affect their survival and 'trap' them in poverty (Comim et al. 2009). Natural resources often serve as de facto safety nets for the poor, especially at times of stress such as poor performance of subsistence agriculture (Pattanayak and Sills 2001). A greater number of poor people suffer from extreme natural disasters due to the facts that they predominate in the areas and under conditions that are more susceptible to damage from these events, they lack the resources to cope with the impacts of these events, and they have less access to social safety nets that alleviate the impacts of these events (UNEP/IISD 2004).

Thus it is generally the poorest who suffer the most from the consequences of pollution and environmental degradation, and degraded environments can accelerate the process of impoverishment because the natural assets and common resources that the poor depend directly become less available. They often derive a large part of their livelihoods from nonmarket environmental resources, common grazing lands, or forests where food, fuel, and building materials are gathered. The diminishment or loss of such resources therefore may particularly hurt the poorest and 
undermine their future productivity. Moreover shortages of drinking water or fuel wood tend to affect the poor more than the people with greater means. Environmental degradation depresses people's income by causing them to invest more effort into routine household tasks such as fuel wood and water collection by decreasing the productivity or availability of these natural resources from which they wrest a living. The synergetic interactions between poverty and environmental destruction can lead to a downward spiral of ecological deterioration that threatens the well-being of many of the world's poorest people (Dasgupta 2010).

\subsubsection{Evidence from South Asia and Sub-Saharan Africa}

In response to the growing recognition of the linkages between declining ecosystem services and poverty, conservation organizations and development agencies have been designing and implementing initiatives that focus on maintaining ecosystem services. Although the concept of ecosystem services provides a new platform for the challenge of aligning conservation with development objectives through common links to human well-being, the success of on the ground efforts has been limited. This is due partly to the perception among practitioners that it is difficult to integrate these objectives consistently, as well as some skepticism within the environmental community of the application of an ecosystem services-based approach to conservation (Tallis et al. 2009). Furthermore the availability of robust empirical studies on the nexus between poverty and the environment is limited, particularly due to difficulties in obtaining relevant data from developing countries (Dasgupta et al. 2005).

In the following sections we have highlighted reported examples of the dependence on ecosystem services by people living under extreme poverty from countries in South Asia and Sub-Saharan Africa in order to contribute to awareness of ecosystem management efforts and poverty alleviation. The information on the links between ecosystem services and poverty alleviation summarized in the following sections is drawn from studies undertaken by the Consortium on Ecosystems and Poverty Alleviation (CEPSA) in South Asia (ESPASSA 2008) and Sub-Saharan Africa (Shackleton et al. 2008). The South Asia effort focused on India and the Hindu Kush Himalayan Region including: Bangladesh, Bhutan, Nepal, and Pakistan. South Asia is home to almost one-quarter of the world's population, and has experienced intensive development processes that in many cases have led to severe environmental degradation. The Sub-Saharan Africa component of the study includes eight case studies with in-depth analyses and local information from arid and semi-arid areas of: Botswana, Mozambique, Namibia, South Africa, Swaziland, and Zimbabwe (Shackleton et al. 2008). In arid and semi-arid lands people's dependence on ecosystem services is often high due to limited alternative livelihood options, the fragile nature of these ecosystems, and relatively high risk involved in achieving livelihood objectives (MA 2005b). A brief summary of the links between different types of ecosystem services and poverty based on these studies is provided below. 


\subsubsection{Evidence from South Asia}

In India and the Hindu Kush Himalayan Region rural communities typically depend on 'provisioning services,' or products provided by ecosystems. Forest ecosystems provide resources used for energy, food, animal fodder, medicine, farm implements, and various household assets, and grassland ecosystems provide grazing areas for domestic as well as wild herbivores, although most of the original grasslands of India's Gangetic plains have disappeared due to population pressure.

The livelihoods of a large population of pastoral and agro-pastoral communities in the arid and semi-arid regions of Bhutan, India, Nepal, and Pakistan depend on common pasturelands and free-grazing livestock. The 'provisioning services' provided by freshwater wetlands, such as fish and other aquatic resources were also important to the livelihoods of rural communities. Bangladesh, India, and Pakistan have extensive coastlines that include wetlands and these areas often host dense populations with a high incidence of poverty (ESPASSA 2008).

The wetlands of South Asia are threatened by encroachment, unsustainable harvesting of aquatic resources, industrial pollution, agricultural runoff, and the spread of invasive exotic species. While agro-ecosystems play an important role in the provision of food and fiber for the rural poor, help preserve scenic rural landscapes, and ensure groundwater recharge, they also have negative impacts on ecosystems such as nitrate run-off from cropland to downstream catchments and soil erosion from overgrazed hillsides. Grasslands also provide such ecosystem services as carbon sequestration, methane absorption, and the reduction of nitrogen dioxide emissions. In addition to the provision of wood for fuel and construction, a wide range of ecosystem services provided by mangroves were highlighted, including: shoreline stabilization, storm protection, water quality control, micro-climate stabilization, groundwater recharge, flood control, sediment and nutrient retention, and providing essential habitat for important bird and marine species.

As is the case in Sub-Saharan Africa, the cultural services provided by ecosystems are important in South Asian countries, for example forest and mangrove ecosystems have recreational and tourism value, generating important income for the poor. One example is the Sundarban Tiger Reserve, where part of the extensive mangrove forest spanning the India-Bangladesh border provides livelihood opportunities based on ecotourism (Chopra et al. 2009; Kumar 2012). One of the key findings of the consortium study (EPASSA 2008) in South Asia, however, was the asymmetrical distribution of economic benefits favoring those who can invest and operate in ecotourism over the poor.

\subsubsection{Evidence from Sub-Saharan Africa}

The poor in Sub-Saharan Africa depend heavily on various natural resources for energy needs, food, medicines, construction, crafts, tools, and for ritual and cultural purposes. According to the valuation studies conducted in arid and semi-arid areas of the region reviewed by CEPSA (Shackleton et al. 2008), wild resources 
such as fuel wood, wild foods, and construction materials have significant economic value for rural households with the equivalent income share from these products representing as much as one-third of total household incomes.

Many wild resources such as raw materials, medicines, and botanical oil extracts are traded in local, national, and increasingly, international markets to generate income. The development of natural products for specialized cosmetic, pharmaceutical, food, and health markets is increasingly seen as an opportunity to alleviate poverty while maintaining ecosystem health. A significant proportion of the harvested natural products are for social, spiritual, and cultural purposes, exemplified by the fact that in eastern parts of the cape of South Africa the amount of plant material harvested for cultural uses exceeded that for utilitarian uses (Shackleton et al. 2008).

Natural products are often gathered, used and/or sold in times of crisis to hedge income gaps and to meet specific needs such as school fees or celebration costs. This kind of natural safety net helps the poor reduce household risk and vulnerability, and their ability to cope with difficult events such as drought, disease, the escalation of commodity prices, and conflict. Wild foods and medicinal plants were two of the most common and important uses of natural products relevant to human well-being in the region. The role of wild foods in ensuring household food security and of wild plants used as traditional medicines are important to the poor, though the local extinction of certain species due to commercial overharvesting was also reported in the region (Shackleton et al. 2008). A meta-study undertaken by Vira and Kontoleon (2010) highlighted evidence of the dependence of the poor on biodiversity for their income.

Fuel wood also plays an important role in support of the poor who are reliant on it for household energy and therefore changes in the availability and access to fuel wood can significantly affect their livelihoods and well-being. Fresh water provided by rivers and wetlands is also essential for supporting the poor, for both domestic purposes and for supporting agricultural-based livelihoods. Ensuring sufficient quantities of fresh water is a challenge due to the lack of necessary infrastructure. In relation to regulating services, soil fertility is a key factor that affects the crop production capacity of the poor. Declines in soil fertility potentially deepen poverty levels through various mechanisms, such as reducing crop yields that in turn decreases sales and income, contributing to food insecurity, and diverting scarce cash resources from other needs to purchase food and/or fertilizers. The flood control services provided by natural wetlands in arid and semi-arid areas of southern Africa are important regulating services for the poor. The spiritual, aesthetic, and recreational services provided by ecosystems were also highlighted by the study as important for the poor (Shackleton et al. 2008).

The studies conducted by the Consortium on Ecosystems and Poverty in South Asia and Sub-Saharan Africa (ESPASSA 2008; Shackleton et al. 2008), reported knowledge gaps in the identification of the whole range of ecosystem services and their values. While it is widely recognized that the well-being of the poor is affected by changes in ecosystem services both directly and indirectly, very few existing studies address these mechanisms. Furthermore the study in Sub-Saharan Africa (Shackleton et al. 2008) highlighted the fact that most of existing work to date has focused on natural resources, while other types of ecosystem services have not been well captured. Due to the fact that the poor often live in marginal areas that 
are most susceptible to the negative impacts of declining ecosystem services such as flooding, drought, poor air quality, and soil degradation, further work is required to better understand these aspects. It was also noted in that report that ecosystem management projects implemented by various agencies did not adequately consider poverty alleviation issues, highlighting the need for further research and communication of the importance and value of ecosystem services to convince policy-makers and practitioners to integrate conservation and development efforts.

\subsection{Conclusions and Lessons Learned}

- The poor are often more vulnerable to the loss of ecosystem services that result in diminished supplies of natural goods and services. There is often a socioeconomic asymmetry in the benefits from conservation. Those who are not poor often benefit more economically than the poor from environmental conservation efforts, while the poor generally suffer more from environmental degradation. A robust theoretical and implementable framework is required to conceptualize the linkages between poverty and ecosystem services.

- The poor often depend upon ecosystem services, but the nature of this dependence is usually not uniform throughout the year. In most areas there are cyclical annual weather patterns that determine the timing of agricultural activities and natural phenomena like flood and drought. The seasonal patterns of dependence of the poor and their coping strategies require regionally specific and in-depth evaluation.

- In all of the reviewed cases of poverty-ecosystem linkages indicators of the intensity and directionality of linkages were either diffuse or incoherent. Future research should seek indicators that enable more coherent understanding of directionality and appropriate policy approaches.

- We have a limited understanding of the links between poverty alleviation and the range of ecosystem services. Information is particularly limited on how regulatory ecosystem services, many of which are critical for supporting the lives of the poor, affect their well-being. Increased understanding of these linkages is critical for understanding the relationships between ecosystem services and poverty.

Open Access This chapter is distributed under the terms of the Creative Commons Attribution Noncommercial License, which permits any noncommercial use, distribution, and reproduction in any medium, provided the original author(s) and source are credited.

\section{References}

Bandyopadhya J (2002) A critical look at the report of the World Commission on Dams in the context of the debate on large dams on the Himalayan rivers. Int J Water Resour Dev 18(1):127-145

Barbier EB (2010) Poverty, development, and environment. Environ Dev Econ 15(6):635-660

Chopra K, Kapuria P, Kumar P (2009) Biodiversity, land-use change and human well being. Oxford University Press, New Delhi 
Comim F, Kumar P, Sirven N (2009) Poverty and environment links: an illustration from Africa. J Int Dev 22:447-469

Dasgupta P (1995) An inquiry into well-being and destitution. Oxford University Press, New York

Dasgupta P (1997) Environmental and resource economics in the world of the poor. Resources for the Future, Washington, DC

Dasgupta P (2010) Nature's role in sustaining economic development. Philos Trans R Soc B 365:5-11

Dasgupta S, Deichmann U, Meisner C, Wheeler D (2005) Where is the poverty-environment nexus? Evidence from Cambodia, Lao PDR, and Vietnam. World Dev 33(4):617-638

Duraiappah A (1998) Poverty and environmental degradation: a review and analysis of the nexus. World Dev 26(12):2169-2179

ESPASSA Ecosystem Services and Poverty Alleviation Study in South Asia (2008) A situation analysis for India and the Hindu Kush Himalayan region. The Energy and Resource Institute, New Delhi

Hutton D, Haque EE (2004) Human vulnerability, dislocation and resettlement: adaptation processes of river-bank erosion-induced displaces in Bangladesh. Disasters 28(1):41-62

Jodha N (1986) Common property resources and rural poor in dry regions of India. Econ Pol Wkly 21(27):1169-1181

Koziell I, Saunders J (2001) Living off biodiversity: exploring livelihoods and biodiversity, issues in natural resources management. International Institute for Environment and Development, London

Kumar P (2012) Impact of economic drivers on mangroves of Indian Sundarbans: an exploration of missing links. Environ Dev Sustain 14(6):939-953

MA (2005a) Ecosystems and human well-being: general synthesis. Millennium ecosystem assessment. Island Press, Washington, DC

MA (2005b) Ecosystems and human well-being: desertification synthesis. Millennium ecosystem assessment. Island Press, Washington, DC

Mehta AK, Shah A (2006) Chronic poverty in India: overview study, CPRC working paper 7. Chronic Poverty Research Centre, University of Manchester, Manchester

Pattanayak SK, Sills EO (2001) Do tropical forests provide natural insurance? The microeconomics of non-timber forest product collection in the Brazilian Amazon. Land Econ 77(4):595-612

Pearce DW (2005) Investing in environmental wealth for poverty reduction, report prepared on behalf of the poverty environment partnership. United Nations Development Programme, New York

Pearce DW, Warford J (1993) World without end: economics, environment, and sustainable development. Oxford University Press, New York

Pfaff ASP, Kerr S, Hughes RF, Liu S, Sanchez A, Schimel D, Tosi J, Watson V (2000) The Kyoto protocol \& payments for tropical forest: an interdisciplinary method for estimating carbonoffset supply and increasing the feasibility of a carbon market under the CDM. Ecol Econ 35(2):203-221

Shackleton C, Shackleton S, Gambiza J, Nel E, Rowntree K, Urquhart P (2008) Links between ecosystem services and poverty alleviation: situation analysis for arid and semi-arid lands in southern Africa. Consortium on Ecosystems and Poverty in Sub-Saharan Africa, Cape Town. http://www.unpei.org/PDF/preliminaryassessments/Links-Ecosystem-Services-and-PovertyAlleviation.pdf. Accessed 15 Feb 2013

Singh RP, Binswanger H (1993) Income growth in poor dryland areas of India's semiarid tropics. Indian J Agric Econ 48(1):52-64

Speth JG, Haas PM (2006) Global environmental governance. Island Press, Washington, DC

Tallis H, Goldman R, Uhl M, Brosi B (2009) Integrating conservation and development in the field: implementing ecosystem service projects. Front Ecol Environ 7(1):12-20

Tallis H, Pagiola S, Zhang W, Shaikh S, Nelson E, Stanton C, Shyamsundar P (2011) Poverty and the distribution of ecosystem services. In: Kareiva P, Tallis H, Ricketts TH, Daily GC, Polasky S (eds) Natural capital: theory and practice of mapping ecosystem services. Oxford University Press, Oxford, pp 278-293 
UNDP (1997) Human development report 1997. United Nations Development Programme. Oxford University Press, New York

UNEP/IISD (2004) Exploring the links: human well-being, poverty and ecosystem services. United Nations Environment Programme/International Institute for Sustainable Development, Nairobi/Winnipeg

Vira B, Kontoleon A (2010) Dependence of the poor on biodiversity: which poor, what biodiversity? Paper presented at the CPRC international conference 2010, Chronic Poverty Research Centre, University of Manchester, Manchester, 8-10 September 2010

WCED (1987) Our common future. World Commission on Environment and Development, United Nations, New York

World Bank (2000) World development report 2000/2001: attacking poverty. World Bank, Washington, DC

World Bank (2002) Linking poverty reduction and environmental management: policy challenges and opportunities. World Bank, Washington, DC

World Bank (2008) Social dimensions of climate change: workshop report 2008. World Bank, Washington, DC 